\title{
Screening for impaired vision in community- dwelling adults aged 65 years and older in primary care settings
}

\author{
Brenda J. Wilson MBChB MSc, Susan Courage RN BScN, Maria Bacchus MD MSc, James A. Dickinson MBBS \\ PhD, Scott Klarenbach MD MSc, Alejandra Jaramillo Garcia MSc, Nicki Sims-Jones BScN MScN, \\ Brett D. Thombs PhD; Canadian Task Force on Preventive Health Care
}

Cite as: CMAJ 2018 May 14;190:E588-94. doi: 10.1503/cmaj.171430

This guideline is available in French at www.cmaj.ca/lookup/suppl/doi:10.1503/cmaj.171430/-/DC2

Podcasts: author interview at https://soundcloud.com/cmajpodcasts/171430-guide

I mpaired vision is an important health burden in both developed and developing countries, particularly among older adults. ${ }^{1}$ The 2006 Participation and Activity Limitation Survey found that $13 \%$ of Canadians aged 75 years and older had a "seeing limitation," with $31 \%$ described as severe, compared with $0.5 \%$ of those aged 15 to 24 years, with $17 \%$ described as severe. ${ }^{2,3}$ The proportion of adults with vision impairment is expected to double in Canada by 2032, as the population ages., ${ }^{1,2}$

A measured visual acuity of worse than $20 / 40$ is often observed as the threshold at which impaired vision results in functional limitations. ${ }^{4}$ Reduced visual acuity is the result of a poor or distorted image reaching the retina because of refractive errors, corneal opacities or cataracts, retinal disease, or problems with the central processing of visual neural signals. ${ }^{5}$ Impaired vision from refractive error or cataracts can be addressed by corrective lenses or other vision-related treatment, including surgical correction of cataracts, whereas interventions for retinal disease or processing of neural signals depend on the specific nature of the disorder. ${ }^{5}$

Among older adults, impaired vision can have a negative impact on vision-related functioning and quality of life, which may be manifested by decreased participation in social, work or leisure activities, as well as difficulties in family relationships; symptoms of depression; injuries from accidents, including falls; or the loss of driving privileges. ${ }^{6-9}$

Many people with impaired vision become aware of it and obtain help on their own. Self-reported data on vision care from the 2005 Canadian Community Health Survey ${ }^{10}$ showed that 59\% of adults aged 65 years and older had consulted an eye care professional in the previous year. Comprehensive eye examinations for adults aged 65 years and older are covered by most provincial governments across Canada and are usually free at point of care.

It is plausible that screening for impaired vision in primary care settings could be beneficial to individuals who do not recognize that they have a vision-related problem or who recognize a problem but do not seek treatment.

\section{KEY POINTS}

- Impaired vision is a risk factor for functional limitations, fallrelated injuries and quality of life in older people.

- Most provincial governments in Canada cover comprehensive eye examinations by eye care practitioners for adults aged 65 years and older. ${ }^{6}$

- A systematic review found low-quality evidence that screening in primary health care settings for impaired vision in adults aged 65 years and older does not appear to improve vision-related functional limitations or quality of life. ${ }^{5}$

- The task force recommends against screening in primary health care settings for impaired vision in community-dwelling adults aged 65 years or older.

\section{Scope}

This guideline presents evidence-based recommendations for preventing vision-related functional limitations in community-dwelling adults aged 65 years and older by screening them for impaired vision in primary care settings such as physicians' offices or clinics. It updates the previous Canadian Task Force on the Periodic Health Examination 1995 guideline on vision screening, which made a grade $B$ recommendation in support of screening for visual impairment in older adults with diabetes of at least five years' duration. ${ }^{11}$

This guideline is directed at primary care providers who have a generalist understanding of eye health and vision care, but do not have specialist expertise or access to specialized equipment. It does not seek to address vision screening undertaken by professional groups with specific expertise in primary vision care, such as optometrists.

The screening methods considered included both self-report of vision function and objective vision testing. Self-report included structured survey and questions. For objective testing of visual acuity, although there are several tools available, the 


\section{Box 1: Grading of recommendations}

Recommendations are graded according to the Grading of Recommendations Assessment, Development and Evaluation system (GRADE). ${ }^{15}$ GRADE offers two strengths of recommendation: strong and weak. The strength of recommendations is based on the balance between desirable and undesirable outcomes; the confidence in the magnitude of the estimates of effect of the intervention on outcomes; the confidence in values and preferences and their variability; and whether the intervention represents a wise use of resources.

Strong recommendations are those for which the Canadian Task Force on Preventive Health Care is confident that the desirable effects of an intervention outweigh its undesirable effects (strong recommendation for an intervention) or that the undesirable effects of an intervention outweigh its desirable effects (strong recommendation against an intervention). A strong recommendation implies that most individuals will be best served by the recommended course of action and that the recommendation can be adopted in practice or as policy in most situations.

Strong recommendations are normally based on high-quality evidence (i.e., high confidence in the estimate of the effect of an intervention). Strong recommendations may recommend in favour of an intervention (when there is high confidence of benefit) or against an intervention (when there is high confidence of harm). However, there are five circumstances in which the task force may consider a strong recommendation based on low- or very lowquality evidence:

- When low-quality evidence suggests benefit in a life-threatening situation (evidence regarding harms can be low or high);

- When low-quality evidence suggests benefit, and high-quality evidence suggests harm or a very high cost;

- When low-quality evidence suggests equivalence of two alternatives, but high-quality evidence of less harm for one of the competing alternatives;

- When high-quality evidence suggests equivalence of two alternatives, and low-quality evidence suggests harm in one alternative; and

- When high-quality evidence suggests modest benefits, and low- or very low-quality evidence suggests possibility of catastrophic harm.

Weak recommendations are those for which the desirable effects probably outweigh the undesirable effects (weak recommendation for an intervention) or undesirable effects probably outweigh the desirable effects (weak recommendation against an intervention), but appreciable uncertainty exists. Weak recommendations result when the balance between desirable and undesirable effects is small, the quality of evidence is lower, or there is more variability in the values and preferences of patients. Cases in which the balance of cost and benefits is ambiguous, key stakeholders differ about the acceptability or feasibility of the implementation, and the effect on health equity is unclear are likely to result in a weak recommendation. A weak recommendation for a prevention service implies that most people would want the recommended course of action but many would not. For clinicians, this means they must recognize that different choices will be appropriate for each individual, and they must help each patient arrive at a management decision consistent with the patient's values and preferences. Policy-making will require substantial debate and involvement of various stakeholders.

Evidence is graded as high, moderate, low or very low, based on how likely further research is to change our confidence in the estimate of effect. ${ }^{15}$ most frequently used are the Snellen and Early Treatment Diabetic Retinopathy Study charts. ${ }^{12}$

It is expected that patients identified through screening as having potentially impaired vision would be referred to an optometrist or ophthalmologist for assessment and intervention as appropriate.

This guideline does not apply to people with a condition known to predispose to vision impairment, such as glaucoma or diabetes; those who live in full-time residential care; or those who have a diagnosis of dementia.

\section{Methods}

The task force is an independent panel of clinicians and methodologists that makes recommendations on primary and secondary prevention in primary care (www.canadiantaskforce.ca). A working group of five voting task force members developed this recommendation with scientific support from the Public Health Agency of Canada. ${ }^{13}$

The systematic review ${ }^{5}$ on which the recommendation is based was conducted by the Evidence Review and Synthesis Centre at the University of Alberta (Edmonton, Alberta). The working group established the research questions and the analytical framework for the systematic review (Appendix 1, available at www.cmaj.ca/ lookup/suppl/doi:10.1503/cmaj.171430/-/DC1). The protocol ${ }^{14}$ (PROSPERO 2016: CRD42016053088), systematic review and draft guideline were reviewed by content experts, including ophthalmologists, optometrists and epidemiologists, as well as health care stakeholders. Clinical and content experts engage with task force working group members to help them address technical issues and understand important clinical issues, by participating in working group meetings, reviewing key supporting documents for accuracy, and by reviewing the final guideline. Clinical and content experts do not have input into task force recommendations and do not vote on recommendations. Outcomes of screening for impaired vision addressed by the review were mortality, fractures, loss of independence, vision-related function, changes in visual acuity, quality of life, major adverse effects from treatment, and anxiety.

To capitalize on earlier work, the evidence review examined good-quality published systematic reviews to identify studies that met the criteria, and also conducted a new search of the MEDLINE, Embase, Cochrane Library, CINAHL and PubMed databases from 2012 to September 2016 to identify studies published since the earlier reviews. Supplementary searches for grey literature were also conducted. A prepublication search update was performed in October 2017 and evidence updated accordingly.

The task force used the Grading of Recommendations, Assessment, Development and Evaluation (GRADE) approach ${ }^{15}$ to determine the quality of evidence and strength of recommendation (Box 1). The evidence-to-decision framework is provided in Appendix 2 (available at www.cmaj.ca/lookup/suppl/doi:10.1503/ cmaj.171430/-/DC1).

The Knowledge Translation team at St. Michael's Hospital (Toronto, Ontario) engaged members of the public on behalf of the task force at two stages of guideline development. In the first phase, 15 participants aged 58 to 78 years rated outcomes to inform the systematic review, by means of an online survey and a focus group. ${ }^{16}$ In the second phase, 20 participants aged 65 to 
74 years were asked to provide their perspective on the guideline recommendations. ${ }^{17}$

A knowledge translation tool for the guideline was informed by feedback from clinicians and patients and is provided on the task force website (www.canadiantaskforce.ca).

The recommendation was approved by the entire task force and underwent external review by content experts and stakeholders. The Feasibility, Acceptability, Cost, and Equity (FACE) tool ${ }^{18}$ was used by health care stakeholders to gain their perspective on the recommendation (Appendix 3, available at www. cmaj.ca/lookup/suppl/doi:10.1503/cmaj.171430/-/DC1).

\section{Management of competing interests}

Funding for the Canadian Task Force on Preventive Health Care is provided by the Public Health Agency of Canada. The views of the funding body have not influenced the content of the guideline. All task force members are required to disclose financial and nonfinancial conflicts of interest. These conflict of interest statements are made available publicly on the task force website. All task force members declared that they had no conflicts of interest for this guideline. Clinical experts and content experts do not have input into or vote on recommendations and are required to disclose any conflicts of interest at the outset of their participation and annually thereafter. All clinical experts declared that they had no conflicts of interest for this guideline.

\section{Recommendation}

For community-dwelling adults aged 65 years and older, we recommend against screening for impaired vision in primary care settings (weak recommendation; low-quality evidence).

We defined screening as either structured enquiry about vision impairment or objective vision testing, with the expectation of further assessment, referral and possible intervention, as indicated by screening test results and subsequent assessment (Box 2).

The evidence review ${ }^{5}$ identified 15 randomized controlled trials (RCTs) of screening for impaired vision using tests or strategies relevant to primary care settings with study participants of communitydwelling adults aged 65 years or older. ${ }^{19-33}$ The RCTs were conducted in Norway, ${ }^{19}$ Germany, ${ }^{20}$ the United Kingdom, ${ }^{21-25}$ Australia $^{26-29}$ the Netherlands ${ }^{30,31}$ and the United States. ${ }^{32,33}$

Participants were recruited from general practice lists, ${ }^{12,20-}$ 25,29,31-35 community settings, ${ }^{28,30}$ an aged care assessment list, ${ }^{26}$ a home care list $^{19}$ and an insurance company registry. ${ }^{27}$ The number of participants in the trials ranged from 93 to 4340 . In the 11 RCTs in which age was reported, the average age of partici-

\section{Box 2: Recommendation for clinicians and policy-makers}

For community-dwelling adults aged 65 years and older, we recommend against screening for impaired vision in primary care settings (weak recommendation; low-quality evidence).

Screening was defined to include questionnaire-based impairment tests or objective vision testing, with the expectation of further assessment and possible intervention, as indicated by screening test results. pants was 78.5 years. In the remaining 4 RCTs, participant eligibility was specified as at least 70 years of age, ${ }^{23,24}$ at least 75 years of age, ${ }^{20}$ or 74 to 84 years of age. ${ }^{30}$ In the 11 RCTs s $^{19,20,22,25-28,30-33}$ that reported sex, $63 \%$ of participants were female.

In 13 RCTs, ${ }^{19-25,27,29-33}$ vision screening took place within a broader assessment of multiple health and functional domains, whereas in two RCTs, ${ }^{26,28}$ vision screening was the only intervention provided. The two types of screening approaches (used alone or in combination) were self-report of visual function using a questionnaire and objective vision testing using one or more charts. In three RCTs, ${ }^{20,25,33}$ the screening test consisted of a questionnaire-based impairment test. In two RCTs, ${ }^{29,30}$ a questionnaire was followed by eye testing with a Snellen chart for patients who reported a problem. In seven RCTs, ${ }^{19,21-24,29,30}$ screening was done by a nurse; in four, ${ }^{25-28,32}$ by another trained individual; and in one, ${ }^{31}$ by a physician. In the three remaining RCTs, ${ }^{20,25,33}$ patients were asked to mail in a questionnaire designed to identify indicators of potential visual impairment.

In all RCTs, following a positive screening result, the patient's physician was notified or a direct referral was made to an eye care professional. In one RCT, specific advice on improving vision was offered to the patient, ${ }^{29}$ and in two others, advice on home lighting improvements was provided. ${ }^{21,27}$ The maximum duration of follow-up, or ongoing interactions after screening, was 2.5 to 47 months (mean 19 mo) after the initial screen. In 10 RCTs, ${ }^{21,23-}$ $26,28-30,34,35$ the control group received some form of vision assessment without active follow-up.

The systematic review identified no evidence on the impact of vision screening on mortality, loss of independence, serious adverse effects from treatment, or on anxiety or stress from positive screen results.

As indicated in Table 1, two RCTs ${ }^{28,29}$ provided very low-quality evidence of an uncertain effect of vision screening on reducing fractures, ${ }^{5}$ using falls as a surrogate outcome. One $\mathrm{RCT}^{28}$ reported an absolute risk reduction (ARR) in the intervention group of 163 fewer falls per 1000 people screened (ARR 16.3\%; 95\% confidence interval [Cl] 28 to 292 fewer) and an ARR of falls requiring medical treatment of 48 fewer per 1000 people screened (ARR 4.8\%; 95\% Cl 12 to 75 fewer), but the authors reported that very few people participated in the vision intervention and indicated that the effect was more likely attributable to the exercise component of the intervention. The other $\mathrm{RCT}^{29}$ indicated a nonstatistically significant absolute risk increase of 20 more falls per 1000 people screened (absolute risk increase 2.0\%; 95\% Cl 48 fewer to 305 more).

A single $\mathrm{RCT}^{22}$ provided low-quality evidence of no net benefit of screening on long-term vision-related functioning: a mean difference was observed of +0.4 units on a $0-100$ point scale, where higher scores indicate better functioning ( $95 \% \mathrm{Cl} 1.25$ lower to 2.05 higher).

A range of metrics were reported that quantified changes in visual acuity after screening. Four RCTs ${ }^{19,26-28}$ provided moderatequality evidence of no overall benefit of screening on mean change in high-contrast visual acuity over a median of 12 months of followup: the mean difference observed did not meet the threshold for the minimally important difference set for this outcome. A secondary analysis of individual participant data from one of these RCTs ${ }^{27}$ suggested that, in the intervention group, 126 fewer participants 
per 1000 people screened had worse visual acuity (from 62 to 171 fewer), and 73 more per 1000 people screened (from 7 to 185 more) had better visual acuity at six-month follow-up. In addition, lowquality evidence from two RCTs ${ }^{22,26}$ reported that screening was not significantly associated with distance visual acuity over 12 to 47 months of follow-up: an ARR was observed of 67 fewer people per 1000 screened with distance visual acuity of $<20 / 40$ (bilateral) (ARR 6.7\%; 95\% Cl 7 more to 127 fewer). Moderate-quality evidence from $10 \mathrm{RCTs}^{20,21,23-25,29-33}$ showed no net benefit of screening on selfreported vision outcomes over a median of 20 months of follow-up: an ARR was observed of nine fewer people reporting vision issues per 1000 people screened (ARR 0.9\%; 95\% Cl 16 more to 31 fewer).

The seven RCTs $19,22,26,28,29,31,32$ that reported on rates of referrals for those with a positive screen indicated that 29\% to $75 \%$ (median 35\%) of patients were offered a referral. Of these, five ${ }^{19,22,26,29,31}$ reported that $18 \%$ to $96 \%$ (median $68 \%$ ) of patients agreed to a referral. None of the studies reported the proportion of participants already under the care of an eye care professional at the time of screening.

\section{Patient values and preferences}

Focus group and survey participants generally articulated a preference for screening for impaired vision, even though likelihood of benefit is unclear. ${ }^{16}$ However, some expressed concerns about the availability of screening at a population level and worried that a country-wide screening program might waste health care resources. Participants also indicated concerns about the limited time available to complete vision screening tests during appointments with primary care physicians, especially if the individual already accessed care from an eye

Table 1: Outcomes of screening for impaired vision in community-dwelling adults aged 65 years and older in primary care settings

\begin{tabular}{|c|c|c|c|c|c|c|}
\hline Outcome and follow-up period & $\begin{array}{l}\text { No. of } \\
\text { studies }\end{array}$ & $\begin{array}{c}\text { Cases/ } \\
\text { screened } \\
\text { patients }\end{array}$ & $\begin{array}{c}\text { Cases/ } \\
\text { control } \\
\text { patients }\end{array}$ & $\begin{array}{c}\text { Relative risk } \\
(95 \% \mathrm{CI})\end{array}$ & $\begin{array}{l}\text { Absolute difference } \\
\text { per } 1000(95 \% \mathrm{Cl})\end{array}$ & $\begin{array}{l}\text { Quality of } \\
\text { evidence }\end{array}$ \\
\hline
\end{tabular}

Falls (self-report falls as a proxy for

fractures)

Follow-up: range 12 mo to 18 mo $\quad 2$ RCTs

Day et al. ${ }^{28}$

Any fall*

Falls requiring medical treatment*

Newbury et al. ${ }^{29}$

Any fall

Vision-related function and quality of

life (assessed with NEI-VFQ-25; scale

from 0 to $100^{22)}$

Follow-up: median $3.9 \mathrm{yr}$

Change in visual acuity with objective

screening (mean change in high-

contrast distance visual acuity) ${ }^{19,26-28}$

Follow-up: median $12 \mathrm{mo}$

Impaired visual acuity with objective screening $(<20 / 40$ distance visual

acuity: bilateral $)^{22,26}$

Follow-up: range 12 to $47 \mathrm{mo}$

Self-reported vision problems (primarily questionnaire-based impairment tests) ${ }^{20,21,23-25,29-33}$

Follow-up: median 20 mo
$49 / 547$

$75 / 543$

$3 / 44$

1.30

(0.31 to 5.49$)$

4 RCTs

$n=764$

$n=579$

2 RCTs

$290 / 913$

$394 / 1054$

0.82

(0.66 to 1.02$)$

67 fewer

(from 7 more to 127 fewer)

$\oplus \oplus \mathrm{OO}$

Low9

10 RCTs

$1042 / 3767$

$1296 / 4916$

0.97

(27.7\%)

(26.4\%)

163 fewer
28 to 292 fewer)

48 fewer

(12 to 75 fewer)

20 more

(48 fewer to 305 more)

MD 0.4 units higher

(1.25 lower to 2.05 higher)

$\oplus \oplus \mathrm{OO}$

Low

MD - 0.01 logMAR better

$(-0.05$ better to 0.03 worse

$\oplus \oplus \oplus \mathrm{O}$

$1 \mathrm{RCT} \quad n=829 \quad n=978$

Moderate§

Note: $\mathrm{Cl}=$ confidence interval, $\mathrm{MD}=$ mean difference, NEI-VFQ-25 = National Eye Institute Visual Functioning Questionnaire 25, RCT = randomized controlled trial.

*The authors of the study ${ }^{28}$ of an intervention to prevent falls in older adults, which included a vision component, showed that only 26 of the 547 participants who were assigned the vision component actually received treatment; therefore, it is unlikely that the vision treatment had the effect on falls quoted in this table. In particular, the authors of this study ascribe differences in the rate of falls to the exercise component of the intervention. In addition, visual acuity improved marginally among the control group and not at all among the intervention group. No other differences were seen in vision measures, which makes the conclusion that vision screening had an impact on falls unlikely.

TVery serious concerns about an unclear risk of bias, owing to inconsistency from reliance on one trial ${ }^{28}$; about indirectness resulting from surrogate outcomes - $75 \%$ of participants received an intervention that could have confounded risk; and about imprecision, as the optimal information size was not met.

¥Serious concerns about high risk of bias for not blinding personnel, patients and outcome assessors; about high and differential attrition [42\% v. 32\% of those alive]; and about inconsistency arising from unknown effects from other studies.

$\S$ Moderate concerns about four RCTs $s^{19,26-28}$ with unclear risk of bias that used multiple objective screening tools and indirectness, as two of the RCTs ${ }^{19,26}$ included many patients who were receiving home care, and on $\mathrm{e}^{19}$ provided an additional intervention that may have influenced results.

ISerious concerns about inconsistency in one tria ${ }^{26}$ and about imprecision, as the optimal information size of about 200 total events with a control event rate of 0.28 was not met.

${ }^{\star \star}$ Moderate concerns about risk of bias for not blinding personnel or patients in any study, about attrition in one study, ${ }^{23}$ and about allocation concealment. Although there was some

inconsistency ( 2 Cls did not overlap; $I_{2}=29 \%$ ), there were no serious concerns regarding this domain. 
care professional. A systematic review of how older adults value benefits versus harms of impaired vision screening was not conducted owing to the considerable uncertainty about benefits of screening.

\section{Resource use}

Low-quality evidence on outcomes important to patients suggests that vision screening is not an effective strategy for improving vision-related functioning in older adults. Cost-effectiveness was not assessed because, in the judgment of the task force, resource considerations would not change the direction or strength of the recommendation.

\section{Feasibility, acceptability, cost and equity}

Because vision screening for older adults is not currently recommended in Canadian primary care settings, there are no feasibility considerations in relation to the present recommendation. Four health care organizations responded to the FACE survey, ${ }^{18}$ three of which represented eye care professionals and indicated the importance of vision screening. In the judgment of the task force, the recommendation is likely to be both feasible and acceptable in Canadian primary care settings and would neither increase nor decrease equity.

\section{Rationale}

Overall, low-quality evidence was available on the effect of screening for vision impairment in adults aged 65 years and older in primary care settings. There was evidence of no overall benefit to patients from being screened, with the exception of the outcome of falls, which were slightly fewer among those screened. This was observed in a single study ${ }^{28}$ that included an exercise intervention designed to prevent falls in older adults, making interpretation of the impact of the vision screening component uncertain. In the judgment of the task force, benefit from screening older adults for impaired vision has not been shown. Despite no evidence of harms associated with screening older adults for impaired vision, delivering an intervention with no benefit carries an opportunity cost. Therefore, the recommendation is against screening.

The recommendation is weak because of low certainty in the evidence and variability noted in patient preferences. A weak recommendation against screening suggests that primary care providers should not routinely offer screening for visual impairment to asymptomatic community-dwelling adults aged 65 years and older.

\section{Considerations for implementation}

This recommendation applies to community-dwelling adults aged 65 years and older. Subgroups of the population that are known to be at increased risk for impaired vision are not the focus of this recommendation, such as people with diabetes or glaucoma. The recommendation does not apply to people who live in full-time residential care or who have a diagnosis of dementia. Professionals who care for these patients should be alert to their potential for impaired vision.

Some asymptomatic older adults may be interested in vision screening despite the uncertain benefits. It is appropriate to remain alert to the potential benefits of a case-finding approach and to be open to discussion of vision screening. ${ }^{41,42} \mathrm{~A}$ knowledge translation tool for professionals is provided on the task force website (www.

canadiantaskforce.ca) to support such discussions. Should a primary care provider and patient consider vision screening, thought should be given to the process of referrals for the patient to access treatment.

There are no specific requirements for monitoring or evaluation in relation to this recommendation.

\section{Other guidelines}

This guideline is consistent with the recommendation on vision screening for older adults from the US Preventive Services Task Force, which showed there was insufficient information to evaluate the outcome-based balance of risks and benefits. ${ }^{36}$ Professional eye care associations generally recommend that adults aged 65 years and older have regular objective vision testing by an optometrist or other eye professional, with frequency based on age and risk factors. ${ }^{37-40}$ Table 2 provides additional information on vision screening guidelines relevant to primary care.

Table 2: National and international guidelines on screening for impaired vision in older adults in primary care

\section{Organization}

Canadian Task Force on Preventive Health Care (current guideline, 2018)

US Preventive Services Task Force $(2016)^{36}$

Canadian

Ophthalmological

Society $(2007)^{37}$

American Academy of Ophthalmology (2015) ${ }^{38}$

Canadian Association of Optometrists (2013) $)^{39}$

American Optometric Association (2015) ${ }^{40}$
Recommendation

Recommends against screening community-dwelling adults aged $\geq 65 \mathrm{yr}$ for impaired vision in primary care settings (weak recommendation, low-quality evidence). This recommendation applies only to community-dwelling adults aged $\geq 65 \mathrm{yr}$ who are not known to be at increased risk for impaired vision.

States that current evidence is insufficient to assess the outcome-based balance of risks and benefits of screening for visual acuity in primary care settings for the improvement of outcomes in asymptomatic adults aged $\geq 65 \mathrm{yr}$ who do not present to their primary care clinician with vision problems. No recommendation made for or against screening.

Recommends screening in asymptomatic low-risk patients aged $>65 \mathrm{yr}$ at least every two years. Patients aged $>60 \mathrm{yr}$ at higher risk of visual impairment should be assessed more frequently and thoroughly; at least annually.

Recommends comprehensive eye examination that includes visual acuity testing and dilation every one to two years for all adults aged $\geq 65 \mathrm{yr}$ who are not known to be at increased risk for impaired visual acuity and do not have risk factors, or more frequently if risk factors are present.

Recommends annual eye examination for adults aged $\geq 65 \mathrm{yr}$.

Recommends annual comprehensive eye and vision examinations for persons aged $\geq 65 \mathrm{yr}$ for the diagnosis and treatment of sight-threatening eye conditions and the timely correction of refractive errors. 


\section{Gaps in knowledge}

Future trials should evaluate the effectiveness of screening older adults for impaired vision in relation to outcomes important to patients. Complex multicomponent screening interventions that include vision screening require clarity about predicted interactions between vision and other components in improving outcomes. The extent to which the effect of vision screening interventions may be modified by age, functional status or other target population characteristics should be considered.

\section{Conclusion}

The evidence currently available does not support screening by primary care providers of adults 65 years of age and older for impaired vision as a way to prevent functional limitations or other major consequences of impaired vision. Primary care clinicians may consider confirming that older patients have had their vision checked by an optometrist or other ophthalmic primary care professional.

\section{References}

1. Freeman EE, Roy-Gagnon MH, Samson E, et al. The global burden of visual difficulty in low, middle, and high income countries. PLoS One 2013;8:e63315.

2. The 2006 Participation and Activity Limitation Survey: disability in Canada (89628-X). Ottawa: Statistics Canada (updated 2010 Jan. 29). Available: www5. statcan.gc.ca/olc-cel/olc.action?objld=89-628-X\&objType=2\&lang=en\&limit=1. (accessed 2017 Aug 8).

3. Maberley DA, Hollands $\mathrm{H}$, Chuo J, et al. The prevalence of low vision and blindness in Canada. Eye (Lond) 2006;20:341-6.

4. Chan T, Friedman DS, Bradley C, et al. Estimates of incidence and prevalence of visual impairment, low vision, and blindness in the United States. JAMA Ophthalmol 2018;136:12-9.

5. Pillay J, Freeman EE, Hodge W, et al. Screening for impaired visual acuity and vision-related functional limitations in adults 65 years and older in primary health care: protocol for evidence review. Edmonton: Evidence Review Synthesis Centre. Available: http://canadiantaskforce.ca/ctfphc-guidelines/overview/ (accessed 2017 July 9).

6. Jin YP, Trope GE. Eye care utilization in Canada: disparity in the publicly funded health care system. Can J Ophthalmol 2011;46:133-8.

7. Ribeiro MV, Hasten-Reiter Júnior HN, Ribeiro EA, et al. Association between visual impairment and depression in the elderly: a systematic review. Arq Bras Oftalmol 2015;78:197-201.

8. Crews JE, Campbell VA. Vision impairment and hearing loss among communitydwelling older Americans: implications for health and functioning. Am J Public Health 2004;94:823-9.

9. Renaud J, Bédard E. Depression in the elderly with visual impairment and its association with quality of life. Clin Interv Aging 2013;8:931-43.

10. Canadian Community Health Survey - Healthy aging (CCHS). Ottawa: Statistics Canada; 2010 May 12. Available: http://www23.statcan.gc.ca/imdb/p2SV. pl?Function=getSurvey\&SDDS=5146 (accessed 2017 Feb 16)

11. Periodic health examination, 1995 update: 3 . Screening for visual problems among elderly patients. Canadian Task Force on the Periodic Health Examination. CMAJ 1995;152:1211-22.

12. Kaiser PK. Prospective evaluation of visual acuity assessment: a comparison of snellen versus ETDRS charts in clinical practice (an AOS thesis). Trans Am Ophthalmol Soc 2009;107:311-24.

13. Canadian Task Force on Preventive Health Care: procedure manual. March 2014. Available: https://canadiantaskforce.ca/wp-content/uploads/2016/12/ procedural-manual-en_2014_Archived.pdf (accessed 2017 Feb 15).
14. Pillay J, Freeman EE, MacGregor T, et al. Screening for impaired visual acuity and vision-related functional limitations in adults 65 years and older in primary health care: protocol for evidence review. Edmonton: Evidence Review Synthesis Centre; 2016. Available: http://canadiantaskforce.ca/ctfphc-guidelines/overview/ (accessed 2017 Feb 28).

15. Schünemann H, Brożek J, Guyatt G, et al., editors. GRADE handbook. GRADE Working Group; 2013. Available: http://gdt.guidelinedevelopment.org/app/ handbook/handbook.html\#h.17zdc2r2pkyf (accessed 2017 Mar 13).

16. Buckland D, Sayal R, Bashir N, et al. Canadian Task Force on Preventive Health Care: patient preferences for screening and treatment outcomes in considering impaired visual acuity in adults aged 65 and older. Toronto: Li Ka Shing Knowledge Institute, St. Michael's Hospital; 2016.

17. Fredrickson K, Sayal R, Buckland D, et al. Li Ka Shing Knowledge Institute St. Michael's Hospital. Patient preferences for visual acuity screening in adults aged 65 years and older: data summary. 2017.

18. Pottie K, Siu W, Duclos P; Members of the WHO Technical Consultation on Pain Mitigation. New recommendations to prevent pain during immunizations: WHO position paper - September 2015. Vaccine 2016;34:3627-8.

19. Haanes GG, Kirkevold M, Hofoss D, et al. An intervention designed to improve sensory impairments in the elderly and indoor lighting in their homes: An exploratory randomized controlled trial [published erratum in $\mathrm{J}$ Multidiscip Healthc 2015;8:321]. J Multidiscip Healthc 2015;8:11-20.

20. Dapp U, Anders JA, von Renteln-Kruse W, et al.; PRO-AGE Study Group. A randomized trial of effects of health risk appraisal combined with group sessions or home visits on preventive behaviors in older adults. J Gerontol A Biol Sci Med Sci 2011;66:591-8.

21. McEwan RT, Davison N, Forster DP, et al. Screening elderly people in primary care: a randomized controlled trial. Br J Gen Pract 1990;40:94-7.

22. Smeeth L, Fletcher AE, Hanciles S, et al. Screening older people for impaired vision in primary care: Cluster randomised trial. BMJ 2003;327:1027.

23. Vetter NJ, Jones DA, Victor CR. Effect of health visitors working with elderly patients in general practice: a randomised controlled trial. Br Med J (Clin Res Ed) 1984;288:369-72.

24. Vetter NJ, Lewis PA, Ford D. Can health visitors prevent fractures in elderly people? BMJ 1992;304:888-90.

25. Harari D, Iliffe S, Kharicha K, et al. Promotion of health in older people: a randomised controlled trial of health risk appraisal in British general practice. Age Ageing 2008;37:565-71.

26. Tay $T$, Rochtchina E, Mitchell $P$, et al. Eye care service utilization in older people seeking aged care. Clin Experiment Ophthalmol 2006;34:141-5.

27. Lord SR, Tiedemann A, Chapman K, et al. The effect of an individualized fall prevention program on fall risk and falls in older people: a randomized, controlled trial. J Am Geriatr Soc 2005;53:1296-304.

28. Day L, Fildes B, Gordon I, et al. Randomised factorial trial of falls prevention among older people living in their own homes. BMJ 2002;325:128.

29. Newbury JW, Marley JE, Beilby JJ. A randomised controlled trial of the outcome of health assessment of people aged 75 years and over. Med J Aust 2001;175: 104-7.

30. van Rossum E, Frederiks CM, Philipsen $\mathrm{H}$, et al. Effects of preventive home visits to elderly people. BMJ 1993;307:27-32.

31. Eekhof J, De Bock G, Schaapveld K, et al. Effects of screening for disorders among the elderly: an intervention study in general practice. Fam Pract 2000;17: 329-33.

32. Moore AA, Siu Al, Partridge JM, et al. A randomized trial of office-based screening for common problems in older persons. Am J Med 1997;102:371-8.

33. Wagner EH, LaCroix AZ, Grothaus L, et al. Preventing disability and falls in older adults: a population-based randomized trial. Am J Public Health 1994;84: 1800-6.

34. Bailey IL, Lovie JE. New design principles for visual acuity letter charts. Am J Optom Physiol Opt 1976;53:740-5. 
35. McGraw PV, Winn B. Glasgow Acuity Cards: a new test for the measurement of letter acuity in children. Ophthalmic Physiol Opt 1993;13:400-4.

36. US Preventive Services Task Force (USPSTF); Siu AL, Bibbins-Domingo K, Grossman DC, et al. Screening for impaired visual acuity in older adults: US Preventive Services Task Force recommendation statement. JAMA 2016;315:908-14.

37. Canadian Ophthalmological Society evidence-based clinical practice guidelines for the periodic eye examination in adults in Canada. Can J Ophthalmol 2007; 42:39-45, 158-63.

38. Feder RS, Olsen TW, Prum BE, et al.; American Academy of Ophthalmology Preferred Practice Pattern Committee. Comprehensive adult medical eye evaluation 2015. San Francisco: American Academy of Ophthalmology; 2015. Available: www. aao.org/preferred-practice-pattern/comprehensive-adult-medical-eye-evaluation -2015 (accessed 2017 Oct 24).
39. Frequency of eye examinations [CAO policy and advocacy position statement] Ottawa: Canadian Association of Optometrists (updated 2013 July 31). Available: https://opto.ca/sites/default/files/cao_position_statement_-_frequency_ of_eye_examinations.pdf (accessed 2017 Oct 24).

40. Adult vision: over 60 years of age. St. Louis: American Optometric Association (updated 2017). Available: www.aoa.org/patients-and-public/good-vision -throughout-life/adult-vision-19-to-40-years-of-age/adult-vision-over-60-years -of-age?sso=y (accessed 2017 Oct 24).

41. Elwyn G, Frosch D, Thomson R, et al. Shared decision making: A model for clinical practice. J Gen Intern Med 2012;27:1361-7.

42. Barry MJ, Edgman-Levitan S. Shared decision making - pinnacle of patient centered care. N Engl J Med 2012;366:780-1.
This article has been peer reviewed.

Authors: Brenda J. Wilson MBChB MSc, Susan Courage RN BScN, Maria Bacchus MD MSc, James A. Dickinson MBBS PhD, Scott Klarenbach MD MSc, Alejandra Jaramillo Garcia MSc, Nicki Sims-Jones BScN MScN, Brett D. Thombs PhD; Canadian Task Force on Preventive Health Care

\section{Competing interests: None declared.}

Affiliations: School of Epidemiology and Public Health (Wilson), University of Ottawa, Ottawa, Ont.; Public Health Agency of Canada (Courage, Jaramillo Garcia, Sims-Jones), Ottawa, Ont.; Departments of Medicine (Bacchus), and Community Health Sciences (Dickinson), University of Calgary, Calgary, Alta.; Department of Medicine (Klarenbach), University of Alberta, Edmonton, Alta.; Lady Davis Institute (Thombs), Jewish General Hospital and McGill University, Montréal, Que.

Guideline Writing Group: Brenda J. Wilson (voting task force member), Susan Courage (nonvoting science team member), Maria Bacchus (voting task force member), James A. Dickinson (voting task force member), Scott Klarenbach (voting task force member), Alejandra Jaramillo Garcia (nonvoting science team member), Nicki Sims-Jones (nonvoting science team member), Brett D. Thombs (voting task force member).

Contributors: Brenda Wilson, Susan Courage, Maria Bacchus, James Dickinson, Scott Klarenbach, Nicki Sims-Jones, Alejandra Jaramillo Garcia and Brett Thombs contributed substantially to the study concept and design, interpretation of the evidence, and critical revision of the guideline draft. Susan Courage, Nicki Sims-Jones and Alejandra Jaramillo Garcia provided science and logistical support to the writing group. Heather Colquhoun, James Dickinson, Roland Grad, Stéphane Groulx, Scott Klarenbach, Eddy Lang, John Leblanc, Gabriela A. Lewin, Ainsley Moore,
Donna Reynolds, Harminder Singh, Guylène Thériault, Brett Thombs and Brenda Wilson drafted the recommendations. Brenda Wilson, Susan Courage and Nicki Sims-Jones drafted the guideline statement. All of the named authors gave final approval of the version of the guideline to be published and agreed to be accountable for all aspects of the work. All collaborating members of the Canadian Task Force on Preventive Health Care (Heather Colquhoun, Roland Grad, Stéphane Groulx, Eddy Lang, John Leblanc, Gabriela Lewin, Ainsley Moore, Donna Reynolds, Harminder Singh, Guylène Thériault, Marcello Tonelli) also made contributions to the development of the guideline and all gave final approval of the version of the guideline to be published.

Funding: Funding for the Canadian Task Force on Preventive Health Care is provided by the Public Health Agency of Canada. The views of the funding body have not influenced the content of the guideline. The views expressed in this article are those of the task force and do not necessarily represent those of the Public Health Agency of Canada.

Acknowledgements: The authors would like to thank the Alberta Evidence Review and Synthesis Centre team (Lisa Hartling, Jennifer Pillay, Tara MacGregor, Robin Featherstone, Ben Vandermeer) for its evidence review, which supported this guideline; Marion Doull, Prinon Rahman and Ernesto Delgado of the Global Health and Guidelines Division at the Public Health Agency of Canada, who supported the development of the guideline; and the Knowledge Translation Program, Li Ka Shing Knowledge Institute, St. Michael's Hospital, for their contributions to patient engagement and knowledge translation work related to this guideline. They would like to thank Ellen Freeman (School of Epidemiology and Public Health and Department of Ophthalmol- ogy, University of Ottawa, Ottawa, Ont.) and Dr. William Hodge (Schulich School of Medicine and Dentistry, Departments of Epidemiology \& Biostatistics and Ophthalmology, University of Western Ontario, London, Ont.) for assisting as clinical or content experts during the development of this guideline. (Clinical and content experts who have assisted the task force in the guideline process may or may not agree with the task force recommendations.) Additionally, the authors would like to thank the peer reviewers and organizational stakeholders who reviewed provided feedback on the draft guideline and completed the Feasibility, Acceptability, Cost, and Equity tool, including Mathieu Carignan, Canadian Occupational Therapy Low Vision Rehabilitation Network; Walter T. Delpero, Canadian Ophthalmological Society, Ottawa, Ont.; Julia Foster, OCAD University, Toronto, Ont.; Natacha Kuran, Public Health Agency of Canada, Ottawa, Ont.; Matthieu Lafontaine-Godbout, Faculty of Medicine and Health Sciences, University of Sherbrooke, Sherbrooke, Que.; Susan J. Leat, School of Optometry and Vision Science, University of Waterloo, Waterloo, Ont.; Steven Lord, Neuroscience Research Australia, Sydney, Australia; Nicolette McGuire, BC Ministry of Health, Victoria, BC; Linda S. Petty, Adaptive Technology Resource Centre, University of Toronto, Scarborough, Ont.; Gilles Plourde, Health Canada, Ottawa, Ont.; Dallas Seitz, Queens University, Kingston, Ont; Kimberley Simmonds, Alberta Health, Edmonton, Alb.; Enitan Sogbesan, McMaster University/ St. Joseph's Healthcare, Hamilton, Ont.; and Benoit Tousignant, Canadian Association of Optometrists. We also thank those who contributed comments but did not wish to be acknowledged.

Correspondence to: Canadian Task Force on Preventive Health Care, info@canadiantaskforce.ca 